\title{
Improving The Electronic Commerce Development In The Republic Of Uzbekistan
}

\author{
KhayitboyevMuhhammadi associate Professor \\ Candidate Of Economic Sciences At The Tashkent Financial Institute.
}

\section{OchilovIlyosKeldiyorovich associate Professor}

Candidate Of Economic Sciences At The Tashkent Financial Institute.

\author{
MisirovKamoliddin associate Professor \\ Candidate Of Economic Sciences At The Tashkent Financial Institute. \\ mutabarchik@mail.ru
}

\begin{abstract}
The article there consideredforeign experience in the development of electronic commerce on the basis ofthe study of scientific and methodological aspects of the organization and functioning of e-commerce system and revealed possibilities of its application in the Republic of Uzbekistan. There also studied factors affecting development of e-commerce and correlationregression model of predicting the improvement of trade in virtual environment. There identified main directions of increasing the efficiency of e-commerce development in the country and additional information on identified subjects or objects of information exchange in order to differentiate the access to the resources and detect the level of privileges of the subject. Reliability service implements maintenance of indisputability of the subject from participation of evidence or facts on the basis of cryptographic verification. And the article were shows the modern requirements of business there proposed to implement such measures of government regulation as licensing activities, standardization and certification of funds and insurance of electronic commerce entities (elements of unification of state regulation) besides the measures of fiscal, money-and-credit, and international trade policy. It's essential to pay particular attention to the security of electronic transactions. In work we discuss about the issues of structural transformations and development of the sphere of information and communication technologies have been investigated in the Republic of Uzbekistan.
\end{abstract}

Keywords

Information and communication technologies, Internet business, e-commerce, authorized third party, Internet banking, electronic digital signature, electronic payment system.

Article Received: 18 October 2020, Revised: 3 November 2020, Accepted: 24 December 2020

\section{Introduction}

Development of information and communication technologies is a display of formation of innovative information society, the progress of which largely depends on information, knowledge and education. Rapid growth of ecommerce is connected with the development of information infrastructure, improving payment systems and their reliability. E-commerce is an integral part of e-business, which covers the whole system of industrial relations apart from commercial activities.
Maintainingdynamic development of national economy is directly connected withactivating efforts of the state and domestic entrepreneurs on increasing participation in Internet business. Application ofthe theory and methodology of electronic business in Uzbekistan at the expense of the use of modern information technologies, mathematical models and methods will allow solvingefficiently a number of economic problems, including tasks of long-term presence of business structures in target market. 
E-commerce is one of the prospective components of innovative economy. That is why methodology for measuring the level of its growth is in the center of attention of both foreign and domestic scientists and specialists.

The issues concerning theoretical foundations of formation of e-commerce system and entrepreneurship in the sphere of information and communication technologies have beenstudied in the works of such foreign scientists and economists as N. Vulkan, G. Duncan, D. Kozie, M. McCartney, L. Mitchell, A. Sammer, T. Wilson and others.

These problems, organizational and economic issues in e-commerce have beenstudied in the works ofthe following scientists as I.T. Balabanov, L.E. Varakin, N.I. Gerashchenko, A. A. Kantarovich, O. A. Kobelev, G. Ya. Rezgo, L. D. Reiman, V. I. Skiba, I.V. Uspensky, V.V. Tsaryovin near-abroad countries.

In the Republic of Uzbekistan the issues of structural transformations and development of the sphere of information and communication technologies have beeninvestigated by A.N. Aripov, R.I.Isaev, A.A. Dzhurabaev, Kh.A. Mukhitdinov and L.I. Shibarshova. The issues of theory and practice in e-commerce have been researched in the works of R.I. Isaev, T.K.
Iminov, Kh.A. Mukhitdinov.M.M. Yuldashev considered conceptual instrument of the essence of e-commerce system as well. The questions of electronic documents circulation and digital subscription are investigated in the works of R.I.Isaev, P.F.Khasanov, Kh.P. Khasanov and others. Practical examples of econometric analysis in the sphere of ICT have been studied and suggested in the works of S.V. Chepel and L.I. Shibarshova. The works of R.I. Isaev, M.M. Karimov, R.Kh. Khamdamov, Kh.P. Khasanov and others can be marked out among special studies devoted to the information security.

Scientists-economists studied basic theoretical principles of formation and development of electronic commerce, elaborated scientific foundation for the improvement of electronic commerce, prepared the source for their further implementation. Among special studies devoted to information security, there can be singled out the works of R.I.Isaev, M.M.Karimov, R.Kh. Khamdamov, Kh.P. Khasanov and others. The works of M.A. Makhkamova, R.I.Isaev, T.M. Butkeevaareamong them as well.

However, conducted research on the development of electronic commerce showed that some aspects of this issue have not been studied enough despite their versatility and depth.

\section{Methodological principles of the organization and functioning of electronic commerce system}

\begin{tabular}{|c|c|c|c|}
\hline \multicolumn{4}{|c|}{ Table 1 Classification of priority types and development barriers of electronic transactions } \\
\hline & Types & Market environment & Development barriers \\
\hline 1. & State to state & E-government & - low level of security on the Internet and, \\
\hline 2. & State to business & $\begin{array}{l}\text { Public procurements, } \\
\text { submitting } \\
\text { reporting, tax collection, } \\
\text { customs payments, etc. }\end{array}$ & $\begin{array}{l}\text { consequently, high risks to electronic transactions; } \\
\text { - the absence of mechanism of argument solution for } \\
\text { electronic transactions and, consequently, the } \\
\text { impossibility of providing written evidence in the court }\end{array}$ \\
\hline 3. & $\begin{array}{l}\text { State } \\
\text { consumers }\end{array}$ & $\begin{array}{l}\text { Utilities payments and } \\
\text { social payments, etc. }\end{array}$ & $\begin{array}{l}\text { on the fact of virtual transaction; } \\
\text { - the absence of a single reliable information resource }\end{array}$ \\
\hline 4. & $\begin{array}{l}\text { Business-to- } \\
\text { business }\end{array}$ & $\begin{array}{lr}\text { Virtual trading } & \begin{array}{r}\text { floors } \\
\text { auctions, }\end{array} \\
\text { (electronic } & \text { electronic } \\
\text { tenders); } & \text { payment systems, insurance } \\
\text { services } & \end{array}$ & $\begin{array}{l}\text { in all spheres of electronic commerce; } \\
\text { - the complexity of mechanism of cooperation with } \\
\text { international financial institutions; } \\
\text { - high tariffs for Internet services; } \\
\text { - high prices of online stores; }\end{array}$ \\
\hline
\end{tabular}




\begin{tabular}{|l|l|l|l|}
\hline 5. & & $\begin{array}{l}\text { Online shopping, auctions, } \\
\text { electronic } \\
\text { pasiness }- \text { to }-\end{array}$ & $\begin{array}{l}\text { - shortcomings in cooperation with international EDS; } \\
\text { - high prices for goods and services delivery; } \\
\text { electronic } \\
\text { - the absence of licensing and certification procedures } \\
\text { for e-commerce services; } \\
\text { - underdevelopment of issues of standardization and } \\
\text { insurance of operations in electronic commerce; } \\
\text { - the need for specialists in the sphere of electronic } \\
\text { commerce, etc. }\end{array}$ \\
\hline 6. & $\begin{array}{l}\text { Consumers to } \\
\text { consumers }\end{array}$ & $\begin{array}{l}\text { Electronic auctions } \\
\text { electronic bulletin board }\end{array}$ \\
\hline
\end{tabular}

Source: materials are drawn up by authors on the basis of UzACI.

Currently, there is no unity in the approaches to the definition "electronic commerce"in scientific literature. Law of the Republic of Uzbekistan (RUz) "On electronic commerce" is interpreted as "implementation of transactions by parties stipulated by law for actions and operations in negotiating and executing transactions onsailing and delivering goods, operations, provision of services, and accomplishment of other operations in accordance with agreement concluded with the use of information systems aimed at making profit on the basis of electronic procedures" [1]. In modern economic literature there is definition of the concept of "electronic commerce" (EC) it's commercial interaction of business entities through Global Internet [2]. SoG.Ya. Rezgo, L.D. Reiman, V.I. Skibaprevail over the vision of electronic commerce as combination of subjects of commerce and transmission telecommunication environment.M. Yuldashev studied the approaches to this direction deeply in his work [3].

In the course of the study, thereappearedthat it is necessary to consider e-commerce more broadly, including financial institutions that provide electronic payments in virtual environment. In addition, they should include methods for managing e-commerce, especially in connection with country's entry into digital economy. In terms of modern requirements of business there proposed to implement such measures of government regulation as licensing activities, standardization and certification of funds and insurance of electronic commerce entities (elements of unification of state regulation)besides themeasures of fiscal,moneyand-credit, and international trade policy. It's essential to pay particular attention to the security of electronic transactions.

Taking into account theabove-stated we suggest considering "e-commerce"as functionally interconnected complex of entities with the participation of buyers, sellers, financial institutions, elements of unification of state regulation, transaction security, and information and communication technologies on the basis of integrated approach. According toabove-stated definition there have been developed conceptual scheme for interaction of entities of electronic commerce. At the same time theelements of the state regulation arebeyond the system and affect them from outside.

Fundamental types of electronic commerce in international practice and operating in Uzbekistan are presented in table 1 . The main share of ecommerce business relations in world practice falls on points 4, 5, 6. In Uzbekistan, there developed the following companies:

"Companies to company" (B2B), "Companies to consumer" (B2C), "Governmentto companies" (G2B), "Government to Consumers" (G2C) and "Government to Foreign Citizens" (G2F) [4]. Inclusion of important categories "Government to Government", "Government to Business", and "Business to Business" in the theory stipulates that they are today priority for the republic, because they facilitate foreign currency inflowand development of exports of resources, goods and services. There producethe greatest interest categories "State to business", "Business 
tobusiness", "Business toconsumers" in connection with the declaration of 2019 year as the "Year of Active Investment and Social Development" in Uzbekistan.

Obstacles to the development of electronic transactions, including regulatory, economic, organizational, technological, social, personnel and security issues are identified in the study along with the known classification of main types of electronic transactions as models of relationships between participants in e-commerce market. For each factor there assessed reasons that facilitate and refrain the development of ecommerce. The issues of low level security on the Internet as the results to high risks of electronic transactions occupy a special place among the barrier of progress (Table 1.).[5]

Traditional business risks are fully inherent in e-commerce and in addition to that specific risks arising from e-commerce technologiesrevealed as well. In particular they are the risks associated with information security: information privacy risk; information falsification risk; information loss risk; information failure risk.

The reasons for emergence of risks are that they flow from specific threats of electronic commerce, including external (viruses and malware; hacker attacks; fraud; spam; the threat of seizing the intellectual property of copyright holder) and internal threats (information theft; sabotage; the absence of professionalism or negligence of employees). Risks can be classified according to the following criteria: by nature of occurrence; possible consequences; scale; content; area of origin; possible insurance; the types of entrepreneurial activity; possible diversification.

Transactions accomplishedin virtual environment are not registered anywhere and, if necessary, there is no legal evidence of transaction confirmation. In solving arguments and conflicts between the parties, it is impossible to provide legally confirming document on the existence of transaction. There required legally authorized body in the form of certifying center that can issue a certified document on completed transaction.
International practice of solution of the issue is presented as authorized legal body - Trusted Third Party (TTP), certification center that issues certified document on the transaction, so-called "electronic notary". According to ITU recommendations, TTP is an organization or agent that provides one or several security services, and is trusted by another entity according to the activities associated with these security services. Responsibilities of TTP include providing guarantees to participants in cooperation with messages and transactions that are timely and accurately transmitted to the intended recipient, ensuring integrity, authenticity and authorship, and that in case of any arguments, there are certain methods for creating and providing necessary facts confirming performance of actions and the course of events. These guarantees are provided to participants of information interaction in the form of electronic receipts, tags, stamps issued and certified by TTP services. On the basis of international experience, we have proposed approach to creating TTP in Uzbekistan. A block diagram with the participation of the structure is suggested on the basis of the analysis of functioning EC system(Fig. 1.).

TTP technology is based on public key infrastructure (PKI), as technical, organizational and legal component that can provide confidence from the subjects of relations.

TTP services, guidance on their use and TTP service management are defined in ITU Recommendation X.842 (10/2000) Series X: Data transmission networks and open communication system. According to ITU Recommendation X.842 TTP services are additional services in the application of electronic digital signature (EDS) and are recommended for the use by entities that wish to increase reliability and business confidentiality in electronic cooperation.

On the basis of ITU Recommendation there presented principal scheme of TTP operation (Fig. 1.). More than 13 trust services have been determined by Recommendation ITU X.842(Appendix 3). During the analysis, there assigned following services of Trusted Third Party 
as the most significant and necessary element for the development of EC in the Republic:

The attribution service is intended to store additional information on identified subjects or objects of information exchange in order to differentiate the access to the resources and detect the level of privileges of the subject. Reliability service implements maintenance of indisputability of the subject from participation of evidence or facts on the basisof cryptographic verification.

Time break service provides certification of electronic document when it is necessary to indicate the date and time of signing and, therefore there used a guaranteed trusted time source. The service for managing keys and key certificates is responsible for key generation processes, registration and certification of keys, as well as for distribution, installation, storage and cancellation of keys. Certificate management service is intended to organize implementation of certificates of public signature keys and guaranteeing their life cycle; structured publication of signature key certificates and information on revoked certificates; keeping these publications up to date.

Electronic Notary Service provides acknowledgement and certification of a document with the assistance of electronic signature or other means, rendering directory inquiries service in the form of electronic receipt signed by TTP.

Trusted third party along with the listed services arrangeslong-term archival storage of electronic documents, which facilitates active introduction and use of electronic means in everyday life. In future, TTP may differentiate its activities in allocation of additional services: information and marketing, trade and analytical, advertising, information security and consumer rights.

Registration of electronic transactions will give an opportunity to control tax payments in virtual environment and solve the problems of tax evasion of electronic transaction for Government of Uzbekistan. TTP functioning will allow statistical accounting of transactions to operateon the Internet, which is very problematicissue of today. Participation of the structure will increase the dynamics of development of electronic commerce; accelerate the growth rate of electronic commerce in the network as well. TTP can also be used in e-government, electronic payments (transactions) and in informational interaction (EDM).

To solve the problems that hold the use of EC there often implemented Trusted Third Party services in world practice, which is affirmed by the dynamics of EC development in the USA and in Western Europe. The use of TTP services isadvanced as impulse for improvement of EC, representing innovation in EC system.

\section{Results}

Specialists' attention has been focused on the study of various subsystems of electronic business. However, in domestic and foreign literature there is no single methodology for measuring the level of development of electronic commerce. There elaborated one of the methods for predicting dynamics of development of electronic commerce using econometric equations.(Fig 2).[8]

There given the system of interrelated equations below:

1. $\mathrm{LTGDP}=4.68+0.94 * \mathrm{LNEC}$

2. LNEC $=-4.8+0.1 *$ LNIU $+0.07 *$ LAS + $0.033 *$ LNDOM $+0.055 *$ LINV $-1.3112 *$ LNAT

3. $\mathrm{LNIU}=4.34+0.91 *$ LAS $+0.46 *$ LOPER

4. LAS $=-4.044+1.45 *$ LOPER $+0.157 *$ LNDOM

5. $\mathrm{LNDOM}=4.89+0.19 * \mathrm{LINV}+0.072 *$ LNAT $+1.072 *$ LKOL

6. $\mathrm{LINV}=-18.71+2.37 * \mathrm{LDOH}+1.29 *$ LNAT

7. $\mathrm{LKOL}=-11.11-2.74 *$ LNAT $+0.21 *$ LNDOM

8. $\mathrm{LDOH}=4.81+0.505 *$ LNEC $-1.44 *$ LNAT

9. $\mathrm{LOPER}=-5.945+0.154 * \mathrm{LINV}+2.29 *$ LNAT

where LGDP is the trade turnover in GDP, LNEC is the volume of electronic commerce, LNIU is the estimated number of Internet users, 
LKOL is the number of Internet users per 1000 people, LAS is the speed of access to international information networks, LNDOM is the number of domains in the .uz.zone, LINV - the volume of investments in the ICT sector, LNAT - the number of active threats in the zone of the uz domain; $\mathrm{LDOH}$ - income from communication services.

First equation shows that the increase in the share of trade in GDP by 0.94 percentage points is due to the increase in electronic commerce by $1 \%$. This indicates the high contribution of e-commerce development to country's GDP.The second equation characterizes main factors in the development of EC. Among them there allocatedevaluative number of Internet users, the speed of the access to international networks, number of domains in the uz.zone, investments in the ICT sector and security, expressed in the number of active threats in the zone of.uz domain. Among all factors, security has the highest coefficient of impact on the volume of ETs that isan increase in the number of active threats by $1 \%$ which leads to a decrease in electronic commerce by $1.3112 \%$. Thus, it is necessary to note that the security of transactions in the network is the most important factor influencing EC development.

The most important area of social and economic development of Uzbekistan is its participation in formation of global information society. Introduction and accelerated extension of ICT is an influential factor in the development of e-commerce, which, in turn, leads to access to world markets, the development of industrial, trade and economic cooperation between regions and other countries, the increase of distribution channels, creation of new labor markets, capital and competitive economy, as well as stimulating necessary level of trade.

\section{Discussion of the results and conclusions}

Conducted analysis of foreign experience in the development of electronic commerce allows us to draw a number of significant conclusions that should be taken into account for Uzbekistan. Namely: emerging powerful, reliable and safe servers, available for the mass buyer (alternative is block chain), guarantying security of electronic transactions; growth of online culture; presence of well-established telecommunications infrastructure, including regions of the country; credit card prevalence; compliance and improvement of electronic payment systems with foreign payment systems; improvement of mechanism for interaction with international financial institutions; improving fiscal focus of customs operations of international trade; the presence of culture of orders and sales in catalogs; the existence of effective express delivery systems; development of mobile commerce, development of standardization issues in the sphere of electronic commerce, insurance of electronic commerce entities, licensing activities in the sphere of electronic commerce and certification of electronic commerce instruments, lack of human resources in the regions, which impedes involvement of population of the regions in world electronic commerce.[9]

Reasons for not using e-commerce services identified in terms of sociological survey. According to respondents, the main reason is the absence of confidence in this form of trade due to the security factor and possible higher prices. $85.5 \%$ of respondents announced about it. Distrust is largely due to lack of knowledge of the mechanism of electronic commerce $(75.3 \%)$. Almost half of the respondents do not have access to the Internet, a third do not consider it necessary to use electronic commerce services. Significant issue in the organization of electronic commerce is the problem of delivery and its cost, which leads to the increase in the final cost of goods.

The Republic of Uzbekistan is implementing a set of measures aimed at introducing and developing ECs that meet the requirements and rules of international trade, which will allow the republic to become an equal member of WTO and participant in the world market. Customs legislation regulating entrepreneurial activity, for example, in legislation on licensing and certification are being improved here. It's necessary to consider a draft legislation on the 
protection of personal data; to develop standardization the issues in the sphere of ecommerce, insurance of e-commerce entities, licensing of activities in the field of e-commerce and certification of e-commerce instruments, on obligations for electronic transactions; on information security; on electronic stock market; criminal and administrative legislation to strengthen the responsibility of e-commerce participants. It is essential to systematize the subject list of goods accessible to mandatory certification and harmonization with international and national standards in EC sphere.[10]

Elaboration of the conditions of recognition of EDS and certificates of keys of foreign citizens in Uzbekistan in legislative order will help to solve legal side of transboundary cooperation. Conduction of monitoring of regulatory framework of the Republic of Uzbekistan and international legislation permitsdeveloping new regulatory documents aimed at accelerating further development of relations in EC sphere. The absence of human resources in the regions is particularly serious drawback, which impedes involvement of population of regions in the global electronic commerce. It is also necessary to raise mechanism for training e-commerce specialists. One of the most important factor suppressing perfection of EC is the low level of security in the network, which involves the threat of intrusion, theft and fraud in virtual environment, respectively, mistrust among users of EC services.

In order to create conditions for the development of small business and entrepreneurship in EC sphere (for example, administrative, tax, information and other benefits), it is expedient to review income rates and integrated social taxes, customs duties (by creating single customs zone with countries near and far abroad) and simplification of procedures for passing through the customs zone for EC facilities. And it's essential to stimulate the development of EC in rural areas by providing various forms of benefits, preferences, creating mechanism for preferential lending to the population on purchasing ICT products and using
EC services. Establishmentof specialized credit systems for small and medium-sized enterprises using EC services will attract manufacturers of goods and services to online sales, which will create competitiveness in virtual environment.[11]

To increase sales in virtual environment, it is also indispensable to enhance the volume of exports of goods and services via the Internet. Formation of Internet banking system and development of mobile banking will contribute to the growth of remote account management. Development and implementation of electronic insurance system, including Internet insurance for the introduction of EC will increase users' confidence and, consequently, the demand for services in virtual environment. There required constant exchange of positive experience with the countries of near and far abroad in the sphere of informatization. The increase in the number of online stores and expansion of the range of goods and services will lead to lower prices for the delivery of goods via online stores.[12]Improvement of electronic payment system with the expansion of the range of services, including interbank cooperation provides different functioning financial institutions. There realized wide-range application of the use of universal electronic plastic cards to cover all possible types of electronic payments. Formation of favorable conditions will serve for advantageous basis of wide attraction of investments, including foreign, grants from international organizations, financial institutions, companies, firms, etc.[13]

The growth of EC indicators is characterized by prospects and conditions for attracting investments. In the course of studying the infrastructure of EC system there suggested to include the issues of certification of electronic commerce instruments and licensing activities in the sphere of electronic commerce. It's obligatory to take measures to improve certification procedures, which include: simplifying access to the information necessaryfor applicants to receiving certificate in order todetermine technical requirements and procedures; optimizing 
terms of certification procedures that will quickly bring technology to the market; establishing rational payment for conducting certification procedures, including costs on trial, which allow manufacturers to hold control or choose from several test laboratories where exactly appropriate tests should be carried out; introduction of consistent conformity assessment procedures that allow manufacturers to make rational and realistic business plans; automatic renewal of certificates recertification (it is needed to simplify procedures for re-certification in the event that product changes affect technical parameters).

In this regard, the use of specialized software and hardware-software protection instruments that meet requirements of the State certification system on acquisition of information security deserves consideration.

On the assumption of the analysis of foreign and domestic experience, it is indispensable to form transparent conditions for licensing operations in the area of EC. It is reasonable to offer the following recommendations: substitute licensing information protection activities with the replacement of its certification, which will provide the necessary quality of information protection instruments and services for its protection; introduction of mechanism for non-governmental regulation of ICT sector - for example, independent associations, business communities, etc. To determine integrated standards and rules for managing EC in the country and abroad it is necessary to build standardizing system in the sphere of EC. It is significant to introduce international standards in the area of EC and commercial transaction support procedures recognized by international community. It is essential to conduct organizational measures in order to accelerate the development of EC in the country. In order to improve delivery system for goods and services, it is prudent to expand postal and transport services, including application of electronic system for tracking movement of goods. Rural population connection to a single electronic document management will be provided with the further creation of centers for registering EDS keys in the regions.[14]

Establishment of sustainable multi-purpose collective access offices in rural areas (in libraries, educational institutions, post offices) at moderate prices or for free access to various information resources, primarily the Internet, compliance with the intellectual property rights and encouraging the use of information and knowledge sharing will accelerate the process of integrating population of the country into virtual environment. Eradication of computer and Internet illiteracy is possible by encouraging media to promote and implement EC in everyday life. The study and analysis of international trends in the creation and development of electronic commerce shows that it is important to train and retrainpersonnel for working in the sphere of electronic commerce. Therefore it is significant: studying the need for ecommerce specialists, planning and forecasting training specialists, considering global, regional and national trends in the supply and demand of specialists in EC; elaboration of training standards for specialists; improvement of proposals to coordinate training e-commerce specialists in economic sectors; creation of specialized training centers in the sphere of "electronic commerce"; guaranteeing connection of training with production through the organization of placements in the structures involved in EC process; formation of curricula and educational and methodical literature in national language and in various formats for teaching bachelors and masters in the sphere of "electronic commerce"; improving and developing the system of training on the basis of world experience, retraining and advanced training of personnel in the sphere of EC by producing information-marketing and educational-consulting centers; employment of graduates in the direction of "electronic commerce".

Solution of social aspects of electronic commerce services practice in the regions by increasing the culture of their use, producing multi-purpose office of collective Internet access remains as important issue (in libraries, 2816 
educational institutions, post offices) in order to improve public services and improve the quality of life.

Studying national priorities and international requirements for ECthere suggestedto include a list of recommendations in the EC development program in the medium term: to continue working on sustainable improvement of EC by expanding access to national and international infrastructure of EC, including the Internet of wide layers of EC participants; completion of creation of local and corporate information and communication networks in the main sectors of economy; creation and operation of foreign trade information portal; completion of the formation of regulatory framework for EC management, to form the program for the expansion of EC infrastructure; to implement modern electronic document management systems using electronic digital signatures in organizations of various forms of ownership; to complete the development of software products for the organization of electronic trading floors, electronic stores and salons, operation of foreign trade and information portals; to create electronic trading floors in each regional center and monitoring of commodity market; further development of electronic stores, salons in the regions of the country; formation of public procurement system using EC; development of online payment systems and implementation of remote bank account management systems; further development of electronic export site of Uzbekistan; stimulating investment by the private sector, encouraging formation of new applications and developing content, developing partnerships between the public and private sectors, conducting joint events at the national, regional and international levels.

\section{References}

[1] Law of the Republic of Uzbekistan "On Telecommunications" from August 20, 1999, № 822-I.

[2] Law of the Republic of Uzbekistan "On Informatization” from December 11, 2003 № 560-II.
[3] Law of the Republic of Uzbekistan "On electronic digital signature", from December 11, 2003, № 562-II.

[4] Law of the Republic of Uzbekistan № 611-II "On electronic document management", from April 29, 2004

[5] Law of the Republic of Uzbekistan "On Electronic Commerce" from 29.0.2004 № 613-II (Law was adopted in a new version in accordance with the Law of the Republic of Uzbekistan from May 22, 2015,№ ZRU-385 “On Amendments and Additions to the Law Republic of Uzbekistan "On electronic commerce". compiled by authors

[6] Regulations of the President of the Republic of Uzbekistan ShavkatMirziyoyevOliyMajlis-December 28, 2018. Access mode: http://uza.uz/ru/politics/poslanieprezidenta-respubliki-uzbekistan-shavkata-

[7] E-commerce: Tutorial/ Kobelev O.A.; edited by Pirogov S.V., - $4^{\text {th }}$ edition, Revised and add. - M.: Dashkov I. K, 2017 - 684 p.: 60x84 1/16 ISBN 978-5-39401738-4 - Access mode: http://znanium.com/catalog/product/34085 2

[8] Digital economy: management of electronic business and electronic commerce: Monograph/ L.V. Lapidus. M.: INFRA-M, 2018 - 381 p. - (Scientific Thought).www.dx.doi.org/10.12737/mono graphy_5ad4a677581404.52643793.

Access

Mode: http://znanium.com/catalog/product/94544 7

[9] World Trade Organization. http://www.wto.org/

[10] Materials from the official website of Information and Consulting Center for Electronic Business. / http://www.ecommerce.ru

[11] I.B. Partners, LLC http://www.business2business.ru LLC'IB Partners" 
[12] Electronic site of the search engine http://www.google.com

[13] Temirkhanova M. Zh. Ways to improve the accounting for liabilities in the travel agency // European Journal of Economics and management Sciences. 2017. No. 2. P. 3-6. 